GEOCHRONOMETRIA 48 (2021): 253-262

DOI 10.2478/geochr-2020-0004

S sciendo

Available online at

https://content.sciendo.com/view/journals/geochr/geochr-overview.xml

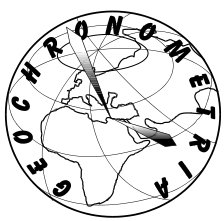

Conference Proceedings of the $5^{\text {th }}$ Asia Pacific Luminescence and Electron Spin Resonance Dating Conference

October $15^{\text {th }}-17^{\text {th }}, 2018$, Beijing, China

Guest Editor: Liping Zhou

\title{
TIMING OF HOLOCENE LAKE HIGHSTAND IN JINCHANG PALEOLAKE FROM THE NORTHEAST TIBETAN PLATEAU FORELAND
}

\author{
HAO LONG ${ }^{1,2}$, HONGYI CHENG ${ }^{3}$, LINHAI YANG ${ }^{4}$, LEI GAO ${ }^{1}$ and QIAN LIU ${ }^{5}$ \\ ${ }^{I}$ State Key Laboratory of Lake Science and Environment, Nanjing Institute of Geography and Limnology, \\ Chinese Academy of Sciences (NIGLAS), 210008 Nanjing, China \\ ${ }^{2}$ CAS Center for Excellence in Quaternary Science and Global Change, 710061 Xi'an, China. \\ ${ }^{3}$ College of Earth and Environmental Sciences, Lanzhou University, 730000 Lanzhou, China \\ ${ }^{4}$ School of Geography and Tourism, Shaanxi Normal University, 710062 Xi'an, China \\ ${ }^{5}$ School of Geography, Nanjing Normal University, 210023 Nanjing, China
}

Received 20 January 2019

Accepted 11 March 2020

\begin{abstract}
Lake shoreline beach ridges and their sediments have often been investigated as paleoenvironmental indicators in arid northern China. Robust chronology is crucial to utilize this archive for paleoenvironmental reconstruction and interpretation. In this study, we reported a robust chronology for the highest wave-built beach ridge around Jinchang paleolake at the northeast (NE) margin of the Tibetan Plateau, using a combined quartz and K-feldspar luminescence dating technique, together with radiocarbon dating. The consistent quartz and K-feldspar ages suggested the sufficient reset of luminescence signals before deposition for the investigated sediments. Both kinds of luminescence ages were in agreement with three independent ${ }^{14} \mathrm{C}$ ages, further corroborating the robustness of these obtained luminescence ages. Our results demonstrated that the investigated beach ridge was formed around 8.5-6.9 ka, suggesting a distinct period of lake highstand which has been identified in other lakes nearby. This highstand event may implicate an increased regional moisture condition, which is likely caused by the increased Asian summer monsoon precipitation.
\end{abstract}

Keywords: luminescence dating, lake highstand, Holocene, paleolake beach, Asian monsoon.

\section{INTRODUCTION}

The paleohydrological variation history inferred from water-level fluctuations of closed lakes has been extensively studied for deciphering the past moisture changes over the Tibetan Plateau and its northern foreland areas

Corresponding author: H. Long

e-mail: longhao@niglas.ac.cn (e.g., Long et al., 2012; Chen et al., 2013; Rades et al., 2015; Long and Shen, 2015), which have been affected by the Asian summer monsoon and the westerlies (An et al., 2012). The exposed beach features and lacustrine sediment remains around closed lake basins can provide direct evidence for the past lake-level changes. A robust geochronological constraint is vital for interpreting and correlating the paleoenvironmental events derived from such fragmentary terrestrial sequences. Age control often relies upon radiocarbon dating of organic matter, which might encounter the following problems: (1) scarcity of 
dating material as low total organic carbon contents of lake sediments in the arid and semi-arid areas (Long et al., 2011), and (2) the vulnerability to contamination by older reworked carbon from the catchment or younger carbon from plant roots or as result of bioturbation (Mischke et al., 2016); additionally, the accuracy of ${ }^{14} \mathrm{C}$ dating could also be biased when using carbonate such as shells because of lake reservoir effect which is likely to vary spatially and temporally (Hou et al., 2012).

Compared with radiocarbon dating technique, optically stimulated luminescence (OSL) can be more practical in dating lake-level related sediments especially from the arid areas owing to widely available dating materials (quartz and feldspar) and a wider age range. Moreover, a luminescence age is entirely independent of variations in lake reservoir effects. However, one common concern about the accuracy of OSL dates may have been associated with the resetting degree of luminescence signals before the deposition, especially for the lacustrine environment. The sediment transport under the water with subdued daylight conditions could potentially result in partial bleaching and hence age overestimation. The degree of bleaching before a deposition can theoretically be evaluated by checking the distribution of equivalent doses $\left(D_{e} s\right)$ and the corresponding statistical analysis based on numbers of small-aliquots or even single-grains (e.g., Wallinga, 2002). As the coarse grained quartz signal of young (e.g., Holocene) beach sediments from arid northern China is relatively dim, large aliquots are normally preferred for the $\mathrm{D}_{\mathrm{e}}$ determination. However, the averaging effects of great numbers of grains on each aliquots could have masked the real bleaching degree (Roberts et al., 2018). Alternatively, comparing ages derived from luminescence signals with different bleaching rates has been used to identify well-bleached quartz (Murray et al., 2012; Reimann et al., 2015; Long et al., 2019). On the other hand, for dose rate calculation the estimation of the past water content for the water-lain sediments is very critical; for a given sample there is typically a $\sim 1 \%$ change in age for every $1 \%$ change in water content (Roberts et al., 2018). Water content may have changed through time due to desiccation or wetting of the lake as well as sediment compaction, and thus the water content value determined in situ may not be able to represent that for the burial time of sediments.

In this study, a major beach ridge from Jinchang paleolake over the northeast (NE) Tibetan Plateau foreland was investigated to reveal the timing of the lake highstand in this area. Both luminescence and radiocarbon dating methods were applied to an outcrop from this beach ridge. To ensure the robustness of the chronological framework, (1) we compared the luminescence ages derived from quartz OSL and K-feldspar signals to test the bleaching degree, and (2) the suitability of an assumed water content value was confirmed by crosschecking of the calculated luminescence age with independent radiocarbon age derived from terrestrial charcoal material. Finally, the timing of the highest wave-built beach ridge in Jinchang paleolake was compared with the lake-level history from adjacent areas, and then its paleoclimatic implication was discussed.

\section{REGIONAL SETTING AND CHRONOLOGICAL SAMPLES}

Jinchang paleolake $\left(\mathrm{N} 38^{\circ} 50^{\prime}, \mathrm{E} 102^{\circ} 20^{\prime}, \sim 1340 \mathrm{~m}\right.$ above modern sea level) is situated over the NE Tibetan Plateau foreland (inset of Fig. 1). The modern climate in this region is dominated by the Asian summer monsoon from July to September, which brings most of the rainfall for the whole year. The cold, dry air masses (i.e., winter monsoon) associated with the Siberian-Mongolian highpressure system generally prevail during the winter (Fig. 1). Nowadays, the lake is dried out; only patchy vegetation, mainly consisting of grass and shrubs, is distributed in places where the groundwater level is close to the ground surface. Geomorphological survey around Jinchang paleolake has demonstrated a series of paleoshoreline features to the east of the lake basin.

We sampled an outcrop named JC section from the highest beach shoreline ridge for dating. The section is about $4 \mathrm{~m}$ thick, and can be roughly divided into four sedimentary units from bottom to top (Fig. 2a): the basal unit (4.0-2.9 m, U1) consists of light-coloured stratified gravelly sands with small numbers of shells and a charcoal layer intercalated at a depth of $3.1 \mathrm{~m}$; the overlying unit (2.9-1.9 m, U2) is pebbly gravels dominant with cross-bedded structures; this unit is covered by a layer of greyish silty sands (1.9-0.8 m, U3) with rich shells at around $1.0 \mathrm{~m}$; the uppermost unit mainly consists of brownish sandy silts $(0.9-0 \mathrm{~m}$, U4). Three samples (NL-579, 580, and 581) were collected for luminescence dating by hammering steel tubes $(5-\mathrm{cm}$ diameter and $20-\mathrm{cm}$ long) into the freshly cleaned profile at the depths of $3.2 \mathrm{~m}, 1.7 \mathrm{~m}$, and $1.0 \mathrm{~m}$ (Fig. 2a). Two shell samples $\mathrm{JC}-1$ and JC-2 (Fig. 2b) for ${ }^{14} \mathrm{C}$ dating were obtained from locations where the two luminescence samples (NL-579 and NL-581) were taken from; another ${ }^{14} \mathrm{C}$ sample was collected from the charcoal layer at a depth of $\sim 3.1 \mathrm{~m}$ (JC-3, Fig. 2c), just overlying the location of luminescence sample NL-579.

\section{DATING EXPERIMENTS}

The sediments were first wet sieved to obtain the coarse grain fraction of 100-200 $\mu \mathrm{m}$ and then treated with $10 \% \mathrm{HCl}$ and $30 \% \mathrm{H}_{2} \mathrm{O}_{2}$ to remove carbonates and organic matter, respectively. Quartz $\left(2.62-2.70 \mathrm{~g} / \mathrm{cm}^{3}\right)$ and K-feldspar $\left(<2.58 \mathrm{~g} / \mathrm{cm}^{3}\right)$ fractions were separated using heavy liquid (sodium polytungstate). The quartz grains were etched with $40 \% \mathrm{HF}$ for $60 \mathrm{~min}$ (followed by an $\mathrm{HCl}$ rinse) to remove the outer alpha-irradiated layer of the quartz grains and also eliminate potential feldspar contamination. We did not etch the K-feldspar grains 


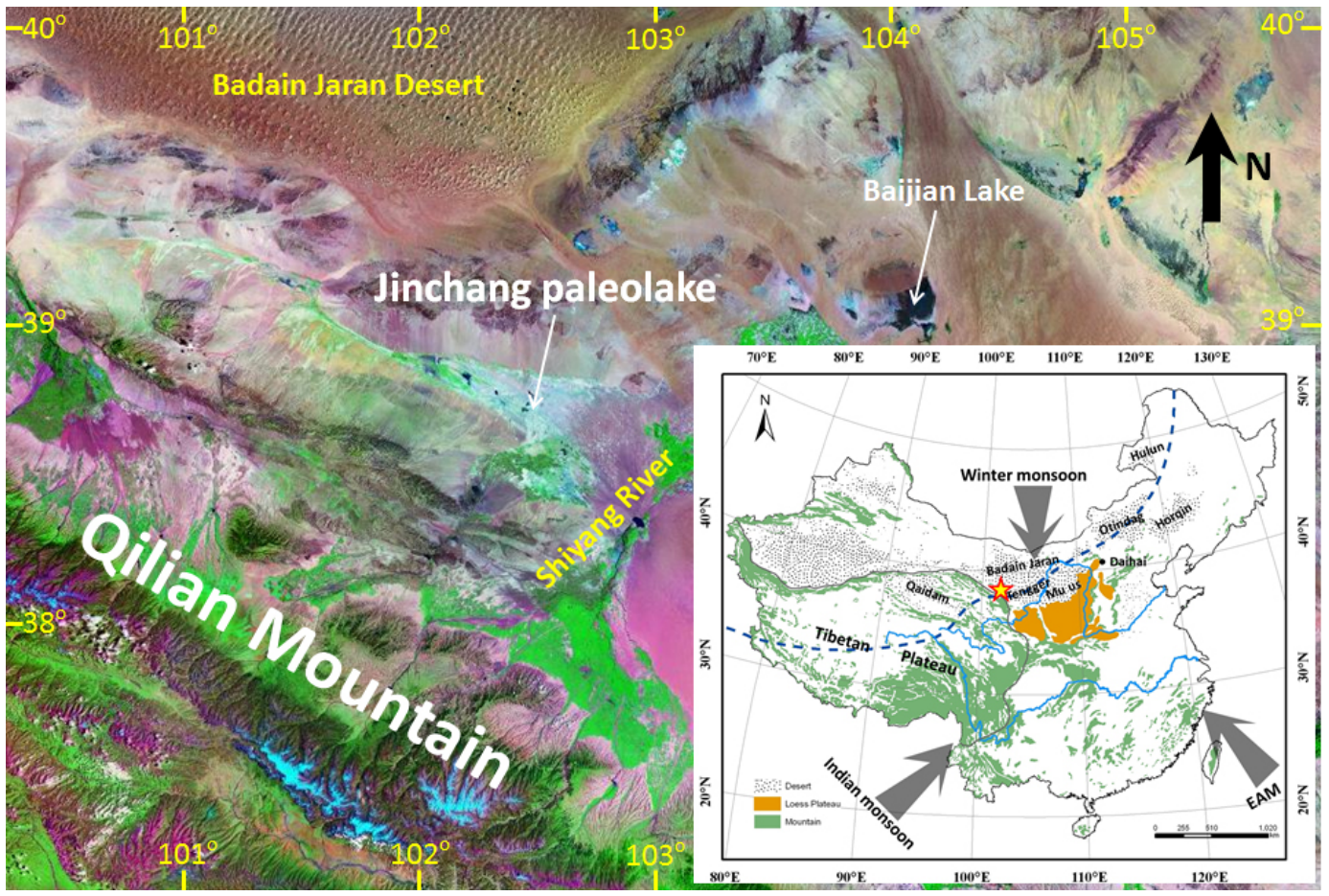

Fig. 1. Map showing the location of Jinchang paleolake (star) and other sites (Baijian Lake, Tegger Desert, Mu us Desert, Otindag Desert and Horqin Desert) mentioned in this study. EAM denotes East Asian monsoon, and its northern limit is shown by the blue dashed line (inset).
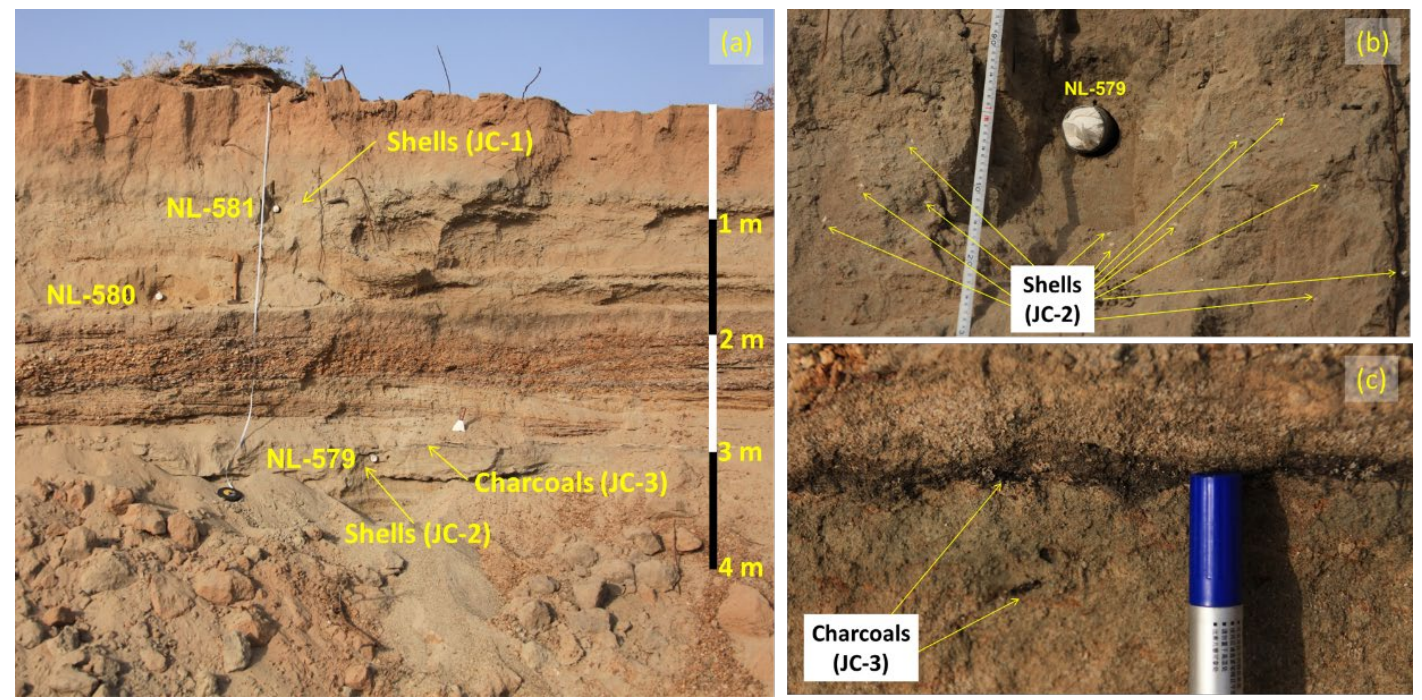

Fig. 2. Photos of outcrop sampled for luminescence and radiocarbon dating.

with HF; instead, the external alpha-irradiated dose rate of K-feldspar grains was taken into account for the total dose rate calculation.

The $D_{e}$ measurements were carried out in the NIGLAS Luminescence Dating Laboratory with an automated Risø TL/OSL DA-20 luminescence reader equipped with a ${ }^{90} \mathrm{Sr} /{ }^{90} \mathrm{Y}$ beta source and a classic stimulation and detection head consisting of blue $(\sim 470 \mathrm{~nm})$ and infrared $(\sim 870 \mathrm{~nm})$ light-emitting diodes. Quartz
OSL was detected through a 7.5-mm-thick Hoya U-340 filter, and infrared stimulated luminescence (IRSL) from K-feldspar was detected through a combination of Schott BG39 and BG3 filters. Due to relatively weak signal intensity, large aliquots $(6 \mathrm{~mm})$ were mounted on stainless steel discs using silicone oil for quartz OSL measurement, and the conventional single aliquot regenerative (SAR) protocol was used to determine $\mathrm{D}_{\mathrm{e}}$ (Murray and Wintle, 2000). The purity of quartz fraction was checked 
by the IR depletion ratio (Duller, 2003), and also by examining the $110^{\circ} \mathrm{C}$ TL peak (Li et al., 2002) in the SAR sequence for each aliquot. Preheat plateau tests were carried out on each of three samples to select the proper measurement condition. Preheat temperatures varied between $160^{\circ} \mathrm{C}$ and $280^{\circ} \mathrm{C}$ at $20^{\circ} \mathrm{C}$ intervals $(3$ aliquots for each temperature), while the cut-heat temperature tracks the preheat temperature by $-20^{\circ} \mathrm{C}$. OSL signals of the first $0.48 \mathrm{~s}$ integral after early background subtraction (from 0.48 to $4.8 \mathrm{~s}$ ) were used for growth curve construction. Twenty aliquots were measured for quartz $D_{e}$ estimation. K-feldspar fraction was prepared with the aliquot size of $\sim 2 \mathrm{~mm}$ diameter, and then measured separately using the two post-IR IRSL (pIRIR) protocols. Following the first stimulation temperature at $50^{\circ} \mathrm{C}\left(\mathrm{IR}_{50}\right)$, the subsequent IR stimulation is recorded at $150^{\circ} \mathrm{C}\left(\mathrm{pIRIR}_{150}\right.$, Madsen et al., 2011; Reimann and Tsukamoto, 2012) or $225^{\circ} \mathrm{C}$ (pIRIR 225 , Thomsen et al., 2008) to obtain pIRIR signals. The preheat temperatures are $180^{\circ} \mathrm{C}$ and $220^{\circ} \mathrm{C}$ for protocols pIRIR 150 and $\mathrm{pIRIR}_{225}$, respectively. For both pIRIR protocols, the test dose was set to $\sim 5 \mathrm{~Gy}$, and the integrated signal was calculated from the first $10 \mathrm{~s}$ minus a background from the last $10 \mathrm{~s}$. Eight discs for each pIRIR protocol were measured for determining the K-feldspar $\mathrm{D}_{\mathrm{e}} \mathrm{s}$.

The concentrations of uranium (U), thorium (Th), and potassium $(\mathrm{K})$ were determined by neutron activation analysis (NAA). Materials were collected in the surrounding of the OSL sampling tube within a radius of $\sim 30 \mathrm{~cm}$, rather than only relying on material from the tube for dose rate measurement. The material was then ground, and $\sim 5 \mathrm{~g}$ of the homogenized material was used for NAA analysis. The conversion factors of Guérin et al. (2011) and the $\beta$-attenuation factors after Mejdahl (1979) were used to calculate the external $\beta$ - and $\gamma$-dose rates. The water content of $10 \%( \pm 5 \%)$ was assumed to correct the $\beta$ - and $\gamma$-dose rates for the water attenuation. For the internal dose rate calculation of K-feldspar, a $\mathrm{K}$ concentration of $12.5 \pm 0.5 \%$ and rubidium $(\mathrm{Rb})$ content of 400 ppm (Huntley and Hancock, 2001) were assumed. The cosmic ray dose rate was estimated for each sample as a function of depth, altitude, and geomagnetic latitude, according to Prescott and Hutton (1994).

${ }^{14} \mathrm{C}$ dating was carried out with accelerator mass spectrometry (AMS) at Rafter Radiocarbon Laboratory (New Zealand). The shell and charcoal samples were cleaned and pretreated with the acid-alkali-acid procedure, prior to combustion, graphitization and ${ }^{14} \mathrm{C}$ measurement. The ${ }^{14} \mathrm{C}$ ages were corrected for fractionation by $\mathrm{d}^{13} \mathrm{C}$ values measured simultaneously and then calibrated to obtain the calendar age (cal a BP) with IntCal13 curve (Reimer et al., 2013).
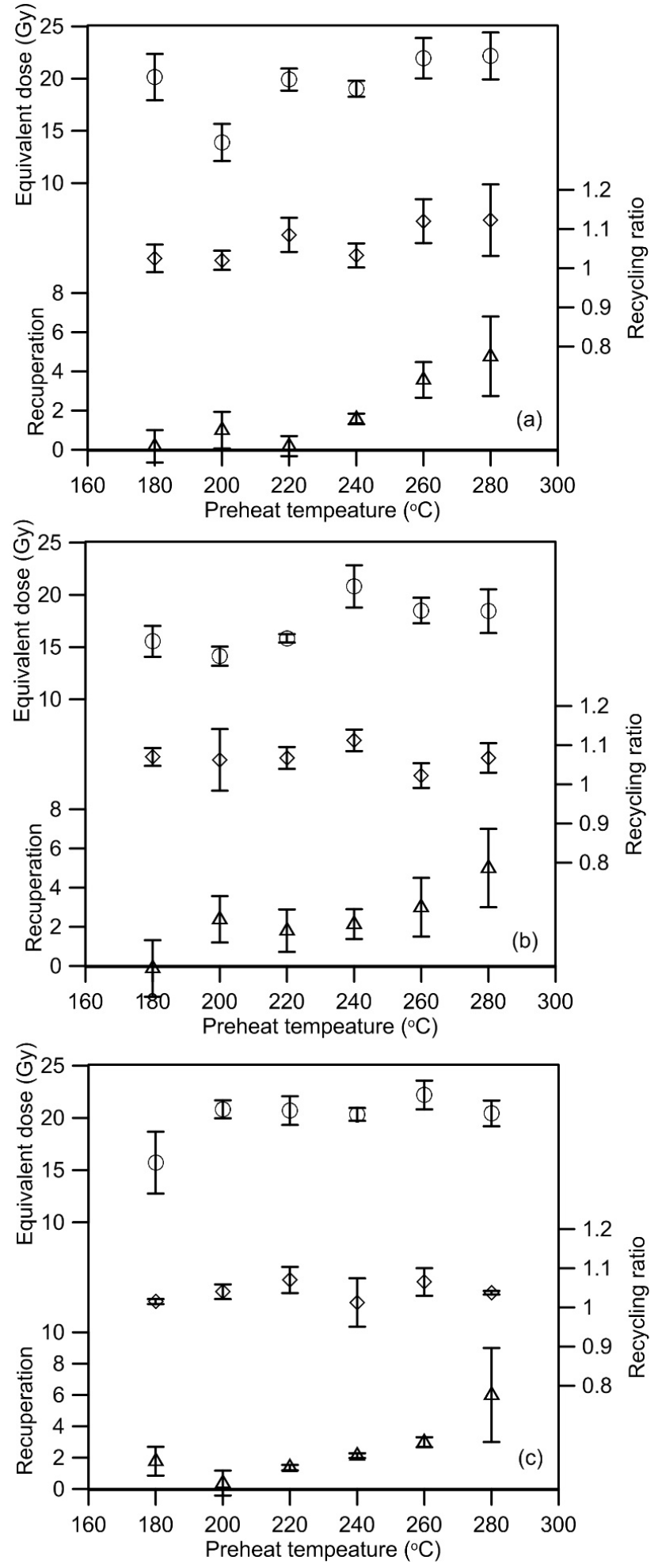

Fig. 3. Preheat temperature plateau tests for quartz samples: NL-579 (a), NL-580 (b), and NL-581 (c). 


\section{RESULTS AND DISCUSSION}

\section{Quartz OSL ages}

Preheat plateau tests were used to assess the performance of the SAR protocol and then choose suitable thermal treatments for $D_{e}$ measurement. As shown in Fig. 3 , the results suggested that recycling ratios were generally between 0.9 and 1.1 , and recuperation (\%) values were generally less than $5 \%$ for all preheat temperatures; a $D_{e}$ plateau was observed between preheat temperature of 220 to $280^{\circ} \mathrm{C}$. Therefore, a preheat temperature at $260^{\circ} \mathrm{C}$ with a cut-heat at $240^{\circ} \mathrm{C}$ was applied for the $\mathrm{D}_{\mathrm{e}}$ determination. The validity of the chosen preheat temperature was further confirmed by dose recovery tests at this fixed combination of preheat and cut-heat temperatures. Twenty-four discs (eight aliquots for each sample) were given to a known beta dose of $\sim 20$ Gy after twice bleaching at room temperature for $100 \mathrm{~s}$ with blue LEDs, with a pause of $5000 \mathrm{~s}$ in between; and then the routine SAR protocol with preheating of $260^{\circ} \mathrm{C}$ and cut-heat of $240^{\circ} \mathrm{C}$ was used to recover the known dose. Fig. 4 presents the summary of dose recovery tests, showing most of the dose recovery ratios are within $10 \%$ of unity. The mean dose-recovery ratio of $1.002 \pm 0.012$ (24 aliquots in total) indicates that the applied SAR protocol can accurately recover a known dose given to a sample before heating and optical treatment.

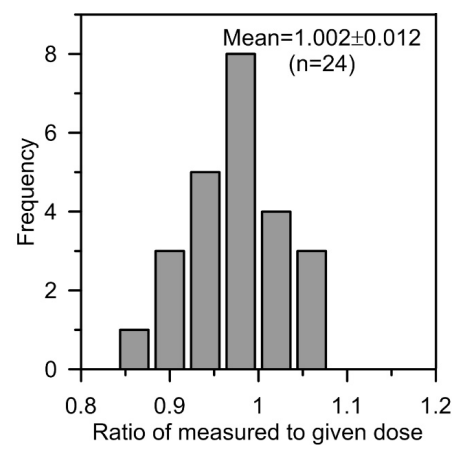

Fig. 4. Histogram summarizing dose recovery ratios for three quartz samples.
The normalized natural OSL decay curve for a representative sample (NL-579) was shown in Fig. 5a; the OSL signals decreased very fast during the first second of stimulation, exhibiting a typical decay curve of quartz minerals. The normalized OSL decay curve can be decomposed into fast, medium and slow components plus backgrounds (BG). For example, the OSL signals from the first $0.48 \mathrm{~s}$ of optical stimulation time are dominated by the fast component (Fig. 5b). The dose-response curve of this sample can be well fitted by single saturating exponential function using six regenerative dose points, including a zero-dose for the measurement of recuperation and a recycling point for assessing the sensitivity change correction. The recycling ratios and recuperation for all $D_{e}$ measurements further suggest the validity of the SAR protocol to these samples. A vast majority of the recycling ratios are within the range of $0.9-1.1$, with a mean of $1.019 \pm 0.005(\mathrm{n}=60)$, and most recuperation values are below $5 \%$.

The $\mathrm{D}_{\mathrm{e}}$ distributions generally suggest normal Gaussian distribution or only slightly skewed (Fig. 6). Central age model (CAM) was used to calculate the ages for $\mathrm{JC}$ section. It has the advantage over the weighted mean of including all the available data without discarding outliers. The summary of the dose rate and age calculation is listed in Table 1. The quartz OSL ages of three samples, range between $\sim 8.5 \mathrm{ka}$ and $\sim 6.9 \mathrm{ka}$, considering the errors.

\section{K-feldspar pIRIR ages}

Fig. $5 c$ and 5d show the natural decay curves of pI$\mathrm{RIR}_{150}$ and pIRIR 225 signals for sample NL-579 together with the corresponding dose-response curves. The efficiency of both pIRIR ${ }_{150}$ and pIRIR 225 protocols was tested using routine performance tests. Following Zhang et al. (2015), the aliquots were bleached for 4 hours in a solar simulator lamp (Hönle SOL2). They were then given a known dose of $\sim 23$ Gy for dose recovery test of pIRIR 150 and pIRIR $_{225}$ protocols. Most measured-to-given dose ratios for pIRIR signals range from 0.9 to 1.1 after subtracting the residual dose values (Fig. 7a). The mean dose-recovery ratios of pIRIR ${ }_{150}$ and $\mathrm{pIRIR}_{225}$ signals are $0.994 \pm 0.002(\mathrm{n}=9)$ and $0.917 \pm 0.004(\mathrm{n}=9)$, respective-

Table 1. Luminescence dating results for three samples.

\begin{tabular}{|c|c|c|c|c|c|c|c|c|}
\hline Sample ID & $\begin{array}{l}\text { Depth } \\
\text { (m) }\end{array}$ & $\begin{array}{c}\mathrm{U} \\
\text { (ppm) }\end{array}$ & $\begin{array}{c}\text { Th } \\
\text { (ppm) }\end{array}$ & $\begin{array}{c}\mathrm{K} \\
(\%)\end{array}$ & Luminescence signals & $\begin{array}{c}\text { Total dose rate } \\
\text { (Gy/ka) }\end{array}$ & $\begin{array}{l}D_{e} \\
(G y)\end{array}$ & $\begin{array}{l}\text { Age } \\
\text { (ka) }\end{array}$ \\
\hline \multirow{3}{*}{ NL-579 } & \multirow{3}{*}{3.2} & \multirow{3}{*}{$2.88 \pm 0.11$} & \multirow{3}{*}{$4.30 \pm 0.16$} & \multirow{3}{*}{$2.13 \pm 0.06$} & $\overline{Q z ~ O S L}$ & $2.82 \pm 0.20$ & $22.1 \pm 1.0$ & $7.8 \pm 0.7$ \\
\hline & & & & & $K$-feldspar pIRIR ${ }_{150}$ & $3.63 \pm 0.22$ & $28.7 \pm 0.7$ & $7.9 \pm 0.5$ \\
\hline & & & & & K-feldspar pIRIR 225 & $3.63 \pm 0.22$ & $26.9 \pm 0.4$ & $7.4 \pm 0.5$ \\
\hline \multirow{3}{*}{ NL-580 } & \multirow{3}{*}{1.7} & \multirow{3}{*}{$2.13 \pm 0.09$} & \multirow{3}{*}{$4.21 \pm 0.16$} & \multirow{3}{*}{$1.87 \pm 0.06$} & Qz OSL & $2.48 \pm 0.17$ & $18.4 \pm 0.6$ & $7.4 \pm 0.6$ \\
\hline & & & & & K-feldspar pIRIR ${ }_{150}$ & $3.26 \pm 0.21$ & $24.4 \pm 0.1$ & $7.5 \pm 0.5$ \\
\hline & & & & & K-feldspar pIRIR 225 & $3.26 \pm 0.21$ & $24.4 \pm 0.6$ & $7.5 \pm 0.5$ \\
\hline \multirow{3}{*}{ NL-581 } & \multirow{3}{*}{1.0} & \multirow{3}{*}{$3.52 \pm 0.12$} & \multirow{3}{*}{$8.02 \pm 0.25$} & \multirow{3}{*}{$1.76 \pm 0.06$} & Qz OSL & $2.91 \pm 0.19$ & $22.2 \pm 0.7$ & $7.6 \pm 0.6$ \\
\hline & & & & & K-feldspar pIRIR ${ }_{150}$ & $3.76 \pm 0.23$ & $28.7 \pm 0.3$ & $7.6 \pm 0.5$ \\
\hline & & & & & K-feldspar pIRIR 225 & $3.76 \pm 0.23$ & $27.9 \pm 0.3$ & $7.4 \pm 0.5$ \\
\hline
\end{tabular}



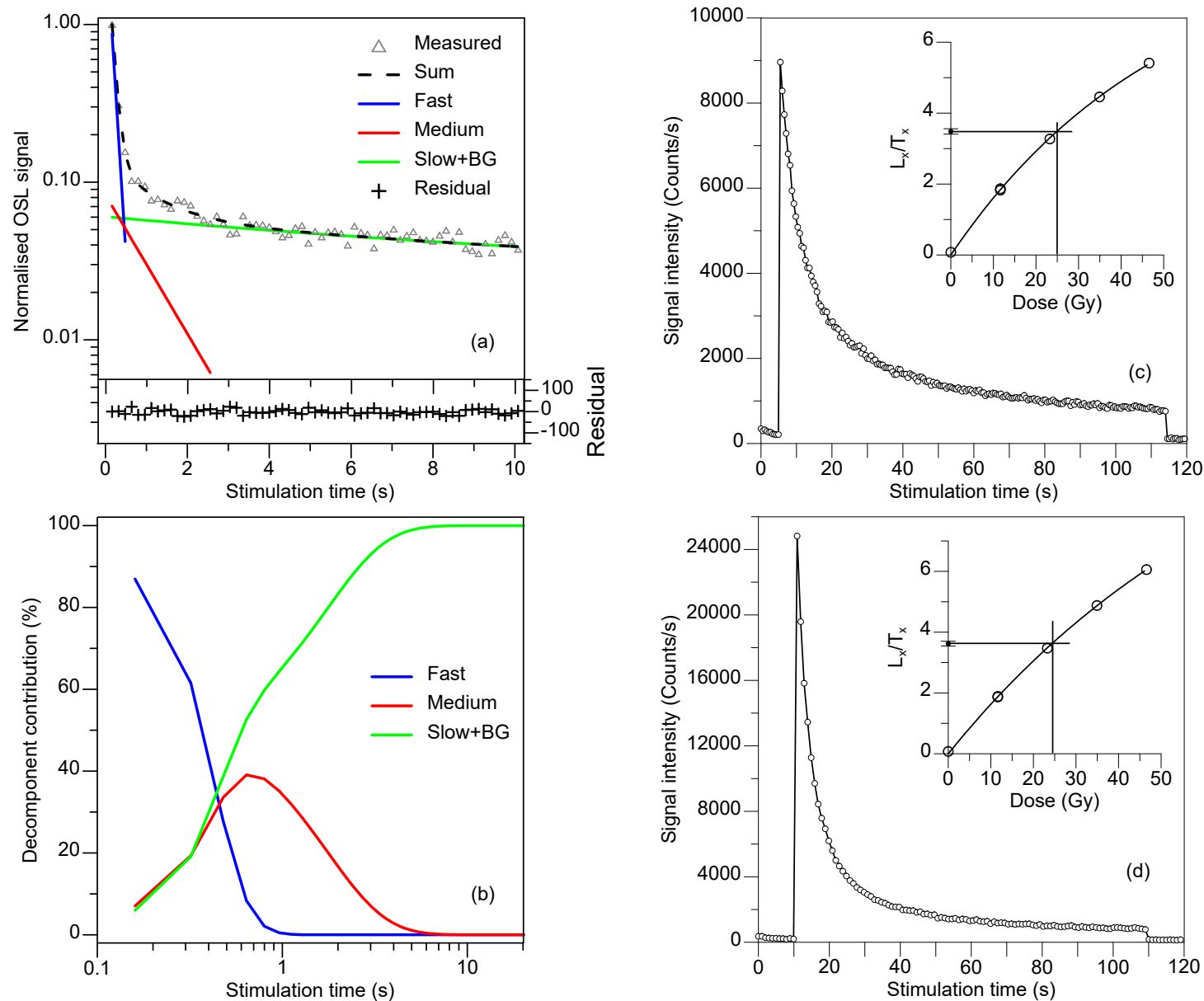

Fig. 5. (a) The normalized OSL decay curve of sample NL-579 was decomposed into three components, i.e., fast, medium and slow plus BG; (b) the relative contribution of the three components are plotted against stimulation time; decay curves and growth curves of K-feldspar plRIR 150 (c) and pIRIR225 (d) signals for sample NL-579.

ly, suggesting that both protocols can accurately recover the doses given in the laboratory before heating and optical treatment. All these laboratory tests indicate that the overall behaviour of the SAR protocol applied to the pIRIR signals from the samples appears to be satisfactory.

Feldspar signal is bleached slower by daylight than the OSL from quartz, and elevated-temperature IRSL bleaches slower than IRSL stimulated at low temperatures (e.g., Reimann and Tsukamoto, 2012). Therefore, the bleachability of the pIRIR signals, which is of particular importance in luminescence dating of young samples, should be examined. We measured the residual doses after bleaching with a solar simulator. Three discs for each sample were exposed in the Hönle SOL2 for 4 hours, and their residual doses range from 0.3 to $0.9 \mathrm{~Gy}$ and from 1.2 to 2.3 Gy for pIRIR 150 and pIRIR $_{225}$, respectively (Fig. 7 b), which are equivalent to approximately $\sim 100-600$ years for the studied sediments. Considering that these residual doses are negligible compared with the natural $\mathrm{D}_{\mathrm{e}}$ values of sediments, and the measured residual dose does not represent the true residual dose in nature
(Kars et al., 2014), the residual doses were not subtracted from the measured $\mathrm{D}_{\mathrm{e}}$ values for age calculation.

Anomalous fading rate of feldspar luminescence signal is usually quantified by the $g$-value to represent the luminescence signal loss per decade of normalized storage time (Huntley and Lamothe, 2001). The fading phenomenon is ubiquitous for the majority of feldspars when the IRSL signal is measured at low temperature (e.g., $50^{\circ} \mathrm{C}$ ). In contrast, pIRIR signal could be used to minimize the fading rate to a negligible level. To confirm this, six aliquots for each sample were measured to determine $g$-values for both pIRIR ${ }_{150}$ and the pIRIR 225 signals as well as the corresponding IRSL $_{50}$ signals using the method described by Auclair et al. (2003). The $g$-value of each aliquot was obtained by fitting a linear regression line to the sensitivity-corrected IRSL and pIRIR signals as a function of logarithmic normalized storage time. It shows a pronounced difference in the slopes of the fitted linear function between the two feldspar signals, which is equivalent to the $g$-value. The mean $g$-values of pIRIR $_{150}$ and pIRIR $_{225}$ of three samples are $1.17 \pm 0.05 \% /$ decade and $0.92 \pm 0.06 \% /$ decade, respectively $(\mathrm{n}=18)$, and the 


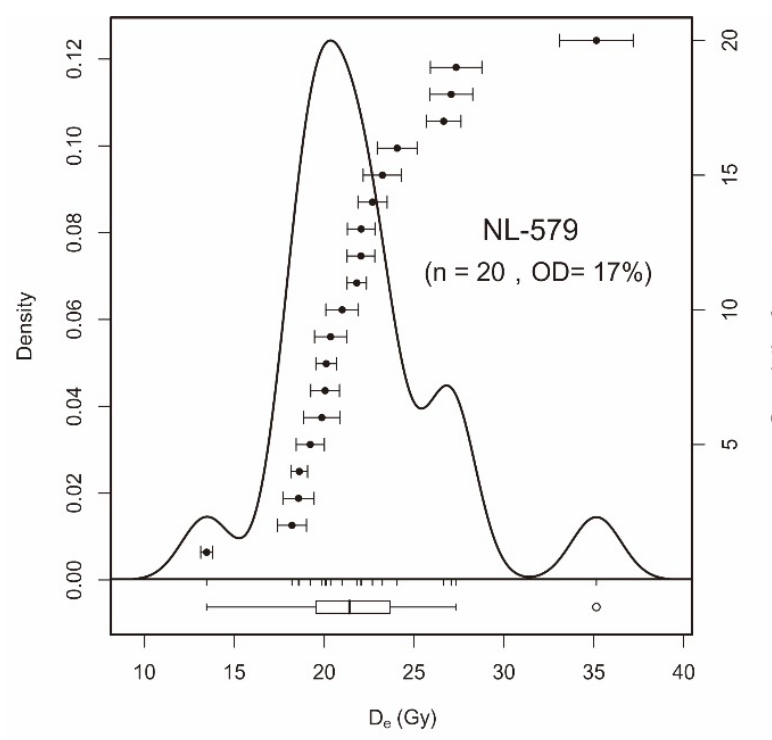

corresponding mean $\mathrm{IRSL}_{50} g$-values are $3.04 \pm 0.04$ $\% /$ decade and $2.56 \pm 0.05 \% /$ decade, respectively $(\mathrm{n}=18)$ (Fig. 7c and 7d). It is obvious that the $g$-values for the pIRIR signal are significantly lower than those derived from the corresponding IRSL $_{50}$ signal.

We prefer not to correct the pIRIR ages for anomalous fading, even though anomalous fading ( $g$-values) was detected for both pIRIR signals. This is because we consider that such low fading rates of $0.9-1.2 \% /$ decade could be a result of laboratory artefact of the fading test measurement, e.g., due to inaccurate sensitivity correction after storage (Buylaert et al., 2012). Previous studies have suggested that corrections based on laboratoryfading rates do not provide accurate age estimates (Li et al., 2008). Furthermore, even standard quartz samples could give a mean $g$-value of $\sim 1.0 \% /$ decade (Buylaert $e t$ al., 2012) (similar to the values for our pIRIR signal), which would predict age underestimates of $\sim 10 \%$ or more. If the pIRIR signal is unstable on a laboratory time scale, it should be similar to the quartz OSL signal, which is generally considered as a stable signal. Thus, our data give evidence that the use of the pIRIR signal can reduce anomalous fading even to a negligible level, and so the equivalent doses derived from the uncorrected pIRIR signal were used for luminescence age calculation.

Following the applied quality tests above, we conclude that the pIRIR protocol is suitable for the determination of $\mathrm{D}_{\mathrm{e}}$ for our K-feldspar samples. The resultant $\mathrm{K}$-feldspar ages are listed in Table 1.

\section{Robustness of luminescence ages and implication for lake highstand}

Laboratory tests of luminescence characteristics above verified the suitability of our measurement conditions. However, the bleaching degree of samples is difficult to be assessed when using large aliquots according to these internal examinations. It is well-known that the IR stimulated signals of feldspar bleach slower than the blue stimulated OSL signals from quartz (e.g., Buylaert et al., 2012). Thus, if luminescence ages derived from quartz and feldspar agree with each other, it is unlikely that the quartz signal was incompletely bleached prior to burial (Murray et al., 2012). For an individual sediment sample, the quartz and feldspar fractions have experienced the same transportation and thus same natural bleaching processes. If the quartz OSL signal is not fully zeroed, the feldspar counterpart must have much larger residual dose and consequently give an older age than the quartz fraction. This approach have been successfully applied to various depositional environments (e.g., Long et al., 2019). For the three samples in this study, the quartz OSL ages of the three samples are in good agreement with the $\mathrm{K}$-feldspar ages derived from both pIRIR ${ }_{150}$ and $\mathrm{pIRIR}_{225}$ signals (Fig. 8), indicating that the quartz OSL signals have experienced complete reset prior to deposition.

Fig. 6. $D_{e}$ distribution of quartz OSL for three samples. 

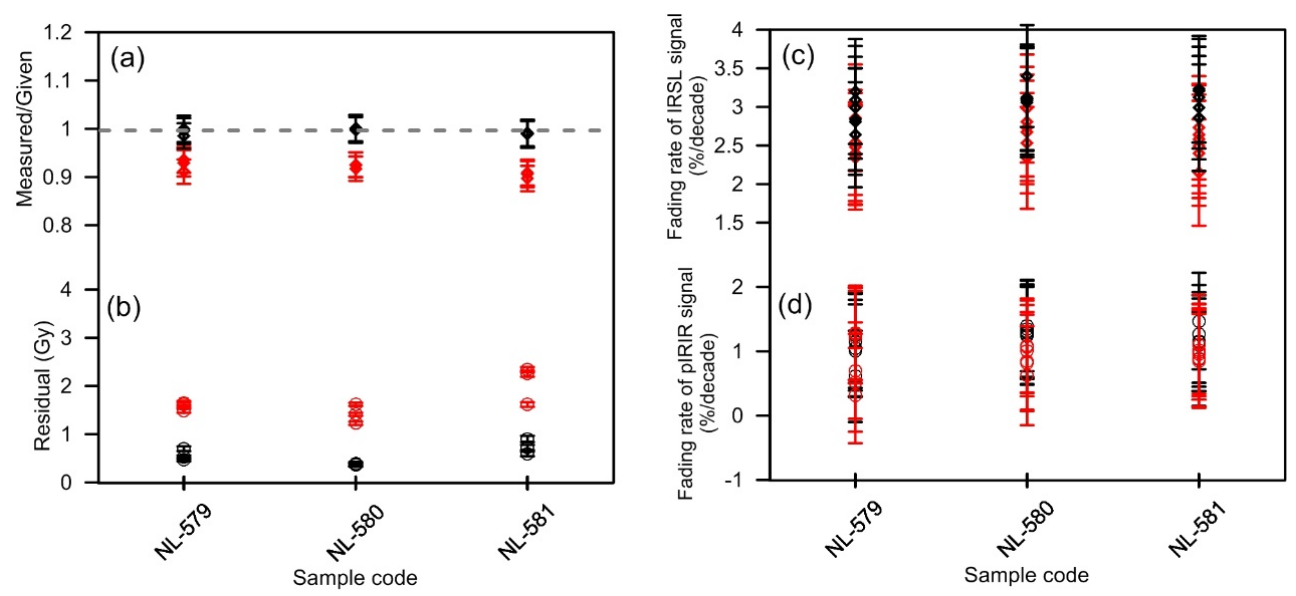

Fig. 7. (a) Dose recovery tests and (b) residual test on K-feldspar pIRIR 150 (black) and pIRIR 225 (red) signals; (c) fading rates of $K$-feldspar pIRIR 150 (black) and pIRIR 225 (red) signals; (d) fading rates of IRSL 50 signals measured by pIRIR150 (black) and pIRIR 225 protocols.

Furthermore, the reliability of luminescence dating results can also be validated by independent radiocarbon age control (Table 2). Terrestrial macrofossils (e.g., charcoals) can yield reliable ${ }^{14} \mathrm{C}$ dates for lake sediments (Edwards and Whittington, 2001). Sample NL-579 yields an OSL age of $7.8 \pm 0.7 \mathrm{ka}$, which is agreeable (within errors) with the ${ }^{14} \mathrm{C}$ age of the charcoal sample (JC-3, 7971-8013 a BP) collected from the horizon overlying the OSL sample (Fig. 8). On the other hand, the accuracy of the OSL ages confirms that the assumed water content value $(10 \%)$ used for dose rate calculation, is realistic for the beach sediments in the study. It is noted that the ${ }^{14} \mathrm{C}$ ages of charcoal (JC-3) and shell (JC-2) in the neighbouring layers have a difference of $\sim 200 \mathrm{a}$, which is probably attributed to a small reservoir effect on shell carbonate ${ }^{14} \mathrm{C}$ age. Our previous study (Long et al., 2011) from the Qingtu Lake (nearby Jinchang paleolake) also showed that the hard water reservoir effect of ${ }^{14} \mathrm{C}$ samples was small, indicated by an apparent agreement between OSL and ${ }^{14} \mathrm{C}$ chronology of the lacustrine sediment, as well as consistent ${ }^{14} \mathrm{C}$ ages dated with different materials (organic and inorganic carbon).

The luminescence and ${ }^{14} \mathrm{C}$ dates of JC section revealed a lake highstand in Jinchang paleolake, which formed from $\sim 8.5$ to $\sim 6.9 \mathrm{ka}$ within uncertainties. On the other hand, these three luminescence ages seem to be identical with each other, probably suggesting the fast sedimentation process over the millennial timescales. In contrast, the more precise radiocarbon ages show a slightly increasing trend downward, and also a very short histo-

Table $2 .{ }^{14} \mathrm{C}$ dating results of three samples.

\begin{tabular}{lcccc}
\hline $\begin{array}{l}\text { Sample } \\
\text { ID }\end{array}$ & Lab ID & $\begin{array}{c}\text { Dating } \\
\text { material }\end{array}$ & ${ }^{14} \mathrm{C}$ ages & $\begin{array}{c}\text { Calibrated ages (Cal a } \\
\text { BP) (one Sigma) }\end{array}$ \\
\hline JC-1 & NZA57145 & Shells & $6868 \pm 26$ & $7668-7764$ \\
JC-2 & NZA47526 & Shells & $7426 \pm 139$ & $8156-8383$ \\
JC-3 & NZA57104 & Charcoals & $7189 \pm 29$ & $7971-8013$ \\
\hline
\end{tabular}

ry of sediment accumulation spanning $\sim 500$ years. Such small time duration can not be identified by OSL dates because of larger uncertainties. It is comparable with the Holocene high lake-level during the time period of $\sim 8-6 \mathrm{ka}$ in the neighboring Baijian Lake (Fig. 1, Long et al., 2012). For the closed lakes from the monsoonal margin, the lake level history reflected the regional moisture condition variations, which in turn related to the strength of Asian summer monsoon (e.g., Sun et al., 2009; Zhang et al., 2016). This highstand event in Jinchang paleolake seems comparable to other Holocene moisture records from the adjacent areas. Based on pollen assemblage and concentration analysis on a lake core, Xiao et al. (2004) reported the wettest stage of 7.9-5.1 ka BP followed by a drying trend in Daihai Lake. Similarly, the Holocene moisture sequence derived from the pollen data of a la-

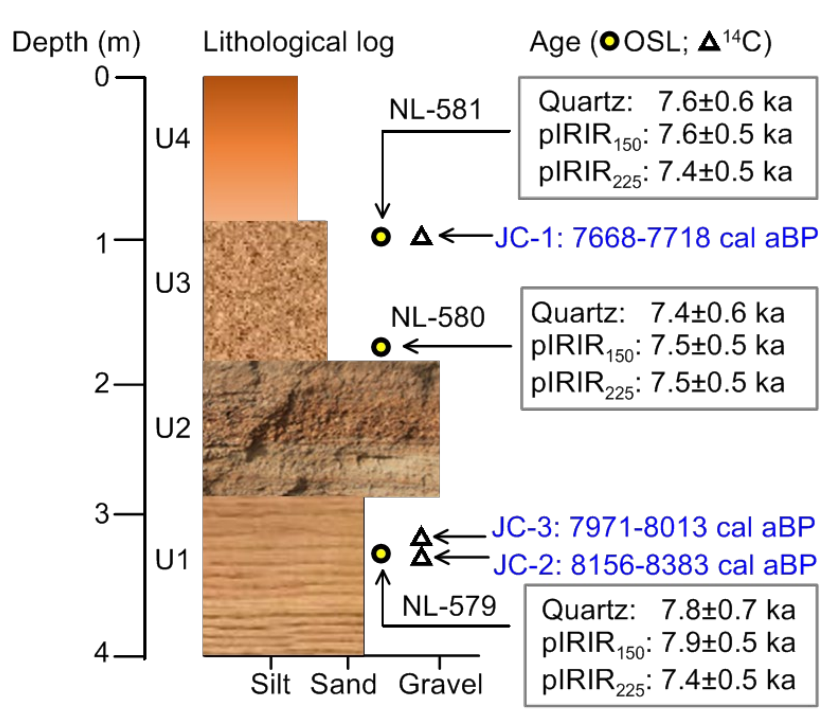

Fig. 8. All luminescence and ${ }^{14} \mathrm{C}$ ages demonstrated together with the lithological log of JC section. 
custrine sedimentary section in Tengger Desert suggested that it was relatively wet at 7.2-5.2 ka BP (Zhao et al., 2008). Based on luminescence dating of several sections from the Mu Us Desert, Otindag Desert and Horqin Desert, it is revealed that sand dunes were mobile at $11.5-8 \mathrm{ka}$ and stabilized at 8.0-6.0 ka, indicating low effective moisture during the Early Holocene and a relatively wetter middle Holocene (Mason et al., 2009). The lake highstand in Jinchang paleolake in this study demonstrated Holocene moisture optimum at around 8.5-6.9 ka, which is generally in line with the previous studies in the adjacent area.

\section{CONCLUSION}

We conducted a comprehensive study of luminescence and radiocarbon dating on a shoreline beach ridge in Jinchang paleolake from the NE Tibetan Plateau foreland. The consistent quartz and K-feldspar ages suggested the sufficient bleaching of OSL signals prior to deposition for the water-lain sediments in the study area; the reliability of the luminescence ages was further confirmed by the independent ${ }^{14} \mathrm{C}$ ages. The chronology obtained by both luminescence and ${ }^{14} \mathrm{C}$ dates manifested that Jinchang paleolake has experienced a lake highstand period from $\sim 8.5$ to $\sim 6.9 \mathrm{ka}$. We considered it as evidence of increased regional moisture in that period over the Asian summer monsoon marginal areas.

\section{ACKNOWLEDGEMENT}

This research was supported by the Strategic Priority Research Program of Chinese Academy of Sciences (No. XDB40010200), the Program of Global Change and Mitigation (No. 2016YFA0600502), the National Natural Science Foundation of China (No. 41977381) and the Youth Innovation Promotion Association CAS grant to HL. We thank anonymous reviewers for helpful comments and suggestions.

\section{REFERENCES}

An ZS, Colman SM, Zhou WJ, Li XQ, Brown ET, Jull AJT, Cai YJ, Huang YS, Lu XF, Chang H, Song YG, Sun YB, Xu H, Liu WG, Jin ZD, Liu XD, Cheng P, Liu Y, Ai L, Li XZ, Liu XJ, Yan LB, Shi ZG, Wang XL, Wu F, Qiang XK, Dong JB, Lu FY and Xu $\mathrm{XW}, 2012$. Interplay between the westerlies and Asian monsoon recorded in Lake Qinghai sediments since $32 \mathrm{ka}$. Scientific Reports 2: 619, DOI 10.1038/srep00619.

Auclair M, Lamothe M and Huot S, 2003. Measurement of anomalous fading for feldspar IRSL using SAR. Radiation Measurements 37: 487-492, DOI 10.1016/S1350-4487(03)00018-0.

Buylaert JP, Jain M and Murray AS, 2012. A robust feldspar luminescence dating method for Middle and Late Pleistocene sediments. Boreas 41: 435-451, DOI 10.1111/j.1502-3885.2012.00248.x.

Chen YW, Zong YQ, Li B, Li SH and Aitchison JC, 2013. Shrinking lakes in Tibet linked to the weakening Asian monsoon in the past 8.2 ka. Quaternary Research 80: 189-198, DOI 10.1016/j.yqres.2013.06.008.
Duller GAT, 2003. Distinguishing quartz and feldspar in single grain luminescence measurements. Radiation Measurements 37: 161165, DOI 10.1016/S1350-4487(02)00170-1.

Edwards KJ and Whittington G, 2001. Lake sediments, erosion and landscape change during the Holocene in Britain and Ireland. $\mathrm{Ca}$ tena 42: 23-73, DOI 10.1016/S0341-8162(00)00136-3.

Guérin G, Mercier N and Adamiec G, 2011. Dose-rate conversion factors: Update. Ancient TL 29: 5-8.

Hou J, D'Andrea WJ and Liu Z, 2012. The influence of ${ }^{14} \mathrm{C}$ reservoir age on interpretation of paleolimnological records from the Tibetan Plateau. Quaternary Science Reviews 48: 67-79, DOI 10.1016/j.quascirev.2012.06.008.

Huntley DJ and Lamothe M, 2001. Ubiquity of anomalous fading in Kfeldspars and the measurement and correction for it in optical dating. Canadian Journal of Earth Sciences 38: 1093-1106, DOI 10.1139/e01-013.

Huntley DJ and Hancock RGV, 2001. The Rb contents of the Kfeldspars being measured in optical dating. Ancient TL 19: 43-46.

Kars RH, Reimann T and Wallinga J, 2014. Are feldspar SAR protocols appropriate for post-IR IRSL dating? Quaternary Geochronology 22: 126-136, DOI 10.1016/j.quageo.2014.04.001.

Li B, Li SH and Wintle AG, 2008. Isochron dating of sediments using luminescence of K-feldspar grains. Journal of Geophysical Research 113: F02026, DOI 10.1029/2007JF000900.

Li SH, Sun JM and Zhao H, 2002. Optical dating of dune sands in the northeastern deserts of China. Palaeogeography, Palaeoclimatology, Palaeoecology 181: 419-429, DOI 10.1016/S00310182(01)00443-6.

Long H, Tsukamoto S, Buylaert JP, Murray AS, Jain M and Frechen M, 2019. Late Quaternary OSL chronologies from the Qinghai Lake (NE Tibetan Plateau): Inter-comparison of quartz and K-feldspar ages to assess the pre-depositional bleaching. Quaternary Geochronology 49: 159-164, DOI 10.1016/j.quageo.2018.11.003.

Long H, Lai Z, Fuchs M, Zhang J and Li Y, 2012. Timing of Late Quaternary palaeolake evolution in Tengger Desert of northern China and its possible forcing mechanisms. Global and Planetary Change 92-93: 119-129, DOI 10.1016/j.gloplacha.2012.05.014.

Long H, Lai Z, Wang N and Zhang J, 2011. A combined luminescence and radiocarbon dating study of Holocene lacustrine sediments from arid northern China. Quaternary Geochronology 6: 1-9, DOI 10.1016/j.quageo.2010.06.001

Long $\mathrm{H}$ and Shen J, 2015. Underestimated ${ }^{14} \mathrm{C}$-based chronology of late Pleistocene high lake-level events over the Tibetan Plateau and adjacent areas: Evidence from the Qaidam Basin and Tengger Desert. Science China Earth Sciences 58: 183-194, DOI 10.1007/s11430-014-4993-2.

Madsen AT, Buylaert JP and Murray AS, 2011. Luminescence dating of young coastal deposits from New Zealand using feldspar. Geochronometria 38: 378-390, DOI 10.2478/s13386-011-0042-5.

Mason JA, Lu H, Zhou Y, Miao X, Swinehart JB, Liu Z, Goble RJ and Yi S, 2009. Dune mobility and aridity at the desert margin of northern China at a time of peak monsoon strength. Geology 37: 947-950, DOI 10.1130/G30240A.1.

Mejdahl V, 1979. Thermoluminescence dating: Beta-dose attenuation in quartz grains. Archaeometry 21: 61-73, DOI 10.1111/j.14754754.1979.tb00241.x.

Mischke S, Lai Z, Long H and Tian F, 2016. Holocene climate and landscape change in the northeastern Tibetan Plateau foreland inferred from the Zhuyeze Lake record. The Holocene 26: 643-654, DOI 10.1177/0959683615612570.

Murray AS, Thomsen KJ, Masuda N, Buylaert JP and Jain M, 2012. Identifying well-bleached quartz using the different bleaching rates of quartz and feldspar luminescence signals. Radiation Measurements 47: 688-695, DOI 10.1016/j.radmeas.2012.05.006.

Murray AS and Wintle AG, 2000. Luminescence dating of quartz using an improved single-aliquot regenerative-dose protocol. Radiation Measurements 32: 57-73, DOI 10.1016/S1350-4487(99)00253-X.

Prescott JR and Hutton JT, 1994. Cosmic ray contributions to dose rates for luminescence and ESR dating: large depths and long-term time variations. Radiation Measurements 23(2-3): 497-500, DOI 10.1016/1350-4487(94)90086-8. 
Rades EF, Tsukamoto S, Frechen M, Xu Q and Ding L, 2015. A lakelevel chronology based on feldspar luminescence dating of beach ridges at Tangra Yum Co (southern Tibet). Quaternary Research 83: 469-478, DOI 10.1016/j.yqres.2015.03.002.

Reimann T and Tsukamoto S, 2012. Dating the recent past ( $<500$ years) by post-IR IRSL feldspar - Examples from the North Sea and Baltic Sea coast. Quaternary Geochronology 10: 180-187, DOI 10.1016/j.quageo.2012.04.011.

Reimann T, Notenboom PD, Schipper MAS and Wallinga J, 2015. Testing for sufficient signal resetting during sediment transport using a polymineral multiple-signal luminescence approach. Quaternary Geochronology 25: 26-36, DOI 10.1016/j.quageo.2014.09.002.

Reimer PJ, Bard E, Bayliss A, Beck JW, Blackwell PG, Ramsey CB, Buck CE, Cheng H, Edwards RL, Friedrich M, Grootes PM, Guilderson TP, Haflidason H, Hajdas I, Hatté C, Heaton TJ, Hoffmann DL, Hogg AG, Hughen KA, Kaiser KF, Kromer B, Manning ST, Niu M, Reimer RW, Richards DA, Scott EM, Southon JR, Staff RA, Turney CSM, van der Plicht J, 2013. INTCAL13 and MARINE13 radiocarbon age calibration curves $0-50,000$ years Cal BP. Radiocarbon 55: 1869-1887, DOI 10.2458/azu_js_rc.55.16947.

Roberts HM, Bryant CL, Huws DG and Lamb HF, 2018. Generating long chronologies for lacustrine sediments using luminescence dating: a 250,000 year record from Lake Tana, Ethiopia. Quaternary Science Reviews 202: 66-77, DOI 10.1016/j.quascirev.2018.10.037.
Sun QL, Wang SM, Zhou J, Shen J, Cheng P, Xie XP and Wu F, 2009. Lake surface fluctuations since the Late Glaciation at Lake Daihai, north central China: a direct indicator of hydrological process response to East Asian monsoon climate. Quaternary International 194: 45-54, DOI 10.1016/j.quaint.2008.01.006.

Thomsen KJ, Murray AS, Jain M and Bøtter-Jensen L, 2008. Laboratory fading rates of various luminescence signals from feldspar-rich sediment extracts. Radiation Measurements 43: 1474-1486, DOI 10.1016/j.radmeas.2008.06.002.

Wallinga J, 2002. Optically stimulated luminescence dating of fluvial deposits: a review. Boreas 31: 303-322.

Xiao JL, Xu QH, Toshio N, Yang XL, Liang WD and Yoshio I, 2004. Holocene vegetation variation in the Daihai Lake region of northcentral China: a direct indication of the Asian monsoon climatic history. Quaternary Science Reviews 23: 1669-1679, DOI 10.1016/j.quascirev.2004.01.005.

Zhang J, Tsukamoto S, Nottebaum V, Lehmkuhl F and Frechen M, 2015. $D_{\mathrm{e}}$ plateau and its implications for post-IR IRSL dating of polymineral fine grains. Quaternary Geochronology 30 147-153, DOI 10.1016/j.quageo.2015.02.003.

Zhang J, Tsukamoto S, Jia Y and Frechen M, 2016. Lake level reconstruction of Huangqihai Lake in northern China since MIS 3 based on pulsed optically stimulated luminescence dating. Journal of Quaternary Science 31: 225-238, DOI 10.1002/jqs.2861.

Zhao Y, Yu Z, Chen F and Li J, 2008. Holocene vegetation and climate change from a lake sediment record in the Tengger Sandy Desert, northwest China. Journal of Arid Environments 72: 2054-2064, DOI 10.1016/j.jaridenv.2008.06.016. 